\title{
Factors hindering the deployment of female teachers to headship positions in public primary schools in Nambale Sub-County, Kenya
}

\author{
Joseph, O. Mukolwe ${ }^{1 *}$, Okwara Michael ${ }^{2}$ and Ajowi, O. Jack ${ }^{3}$ \\ Jaramogi Oginga Odinga University of Science and Technology, Kenya.
}

Received 9 September, 2015; Accepted 22 December, 2015

\begin{abstract}
Worldwide, women representation in management and leadership positions is marginal. Despite immense academic advancement by women, few of them do advance to management positions. In Kenya, women make up a critical portion of human resource base. However, they are grossly underrepresented at leadership positions. This situation is reflected in school leadership positions as well, including headship of schools. Unless the gender gaps in management and leadership positions are addressed, the talent of high skilled women would be underutilized and there might be a reproduction of gender inequality across generations. The purpose of this study was to examine the factors hindering the deployment of female teachers to headship positions in public primary schools. The main objective of this study was to establish the extent to which the two-thirds gender policy was being applied in deployment of female teachers to headship positions. This study was conducted in Nambale Sub-county. Descriptive survey design was used in this study. Out of a study population of 519 respondents comprising 45 head teachers, 45 deputy head teachers, 427 teachers drawn from 45 public primary schools in Nambale Sub-County, the District Education Officer (DEO) and District Quality Assurance and Standard Officer (DQASO), stratified sampling technique was employed to select 35 head teachers, 35 deputy head teachers and 196 teachers. Saturated sampling was used to select the DEO and the DQASO. Therefore, a sample size of 268 respondents, representing $52 \%$ of the study population was used in this study. Questionnaires, interview schedule guide and document analysis guide were used as instruments of data collection. Quantitative data were analyzed using frequency counts and percentages. Findings from the study revealed that the Ministry of Education provided for equal opportunities in terms of deployment but the two-thirds gender policy was not applied in deployment of teachers to school headship. Based on these findings, the study proposed that the Teachers Service Commission should come up with clear and precise deployment policies expressed in writing so that their compliance can easily be checked and the Ministry of Education should design a mechanism for implementing the two-thirds gender policy in deployment of teachers to headship positions.
\end{abstract}

Key words: Deployment to headship positions, female teachers, public primary schools.

\section{INTRODUCTION}

Globally, more women than ever are entering the labour force but majority of the top management positions in almost all countries are primarily held by men. Female managers tend to be concentrated in lower management 
positions and have less authority than men (Akpnarposto, 2012; Australian Government, 2011; Barmao, 2013; Elborg-Woytek, 2013).

In spite of significant advances which women have made in many areas of public life in the last two decades in areas of education, they remain severely underrepresented and are therefore still a long way from participating on the same footing as men in management and leadership of public educational institutions. In the year 2012, the global female labour force was estimated at 1.3 billion, about $39.9 \%$ of the total labour force, but greatly underrepresented in decision making and leadership in all areas. The consequence of this gender gap in leadership is that women do not participate fully in decisions that shape their lives, and therefore the countries are not capitalizing on full potential of almost one half of world's human resource available (ILO, 2012; Morley, 2013; World Bank, 2012).

World over, women have become the new majority in the highly qualified talent pool. In Europe and USA, women account for approximately six out of every ten University graduates and in the UK women represent almost half of the labour force (Davies, 2011). However, in U.S.A there is a paucity of women in executive roles (Elly et al., 2011; Kochanowski, 2010; Seliger and Shames, 2009). Although teaching profession in European countries is dominated by women, more so in public primary schools, their participation rate at senior management level is very low (Vassiliou, 2010).

In Uganda, women are still the minority as both heads and deputy head teachers despite the Ugandan constitution of 1995 stating that women shall have a right to equal treatment with men in regards to opportunities in political, economic and social activities. Although women have made important advances in upgrading their academic qualifications making them eligible for promotion to leadership positions, men still dominate administrative positions as both deputy and head teachers in public primary and secondary schools (Kagoda, 2011). The situation is not different in Nigeria where women marginally participate in governance and management of educational institutions and hence remain invisible in leadership positions. For example, in 2013 , women held less than $14 \%$ of the total management positions in Nigerian Public sector (Oti, 2013).

In Kenya, women continue to be marginalized in many areas of society, especially in the sphere of leadership and decision making. According to a survey by the Ministry of Gender (2009), whilst only $30.9 \%$ of those employees in public service were women, $72 \%$ of these were in the lower cadres (Kamau, 2010). Moreover, the management of public primary and secondary schools, including appointment of head teachers, deputy head teachers, senior teachers and heads of departments, shows a trend of general inequalities in gender representation in favour of men resulting in glaring gender gaps (Barmao, 2013; Onyango et al., 2011; Republic of Kenya, 2012a). Much as there is general recognition that there has been improvements in policy and legislative framework for gender equality in the world of work and enforcement of laws, the glaring gaps in top management positions still persist (Osumbah et al., 2011). For example, in Kenya, article 27(8) of the constitution obligates the state to implement the principle that not more than two thirds of members of elective or appointive bodies shall be of the same gender (Republic of Kenya, 2010a). However, of the 43 state corporative appointments so far made in Kenya, only 2 women had been appointed (Standard, 2014, January 18).

Women are grossly underrepresented in governance of public affairs in Kenya. In education, access of women to decision-making positions is minimal, so is representation of women. The Ministry of Education (MOE) in collaboration with its partners developed a gender policy in 2007 with an objective of addressing critical issues related to gender and education. The purpose of the policy was to provide a roadmap for MOE and stakeholders towards the achievement of gender parity in ensuring that both boys and girls, men and women, participate equally in learning and management of education at all levels (Republic of Kenya, 2007). Despite this gender policy, the management of both public primary and secondary schools in Kenya indicates a trend of male dominance (Parsaloi, 2012). Therefore, continued marginalization of women in top management positions is a paradox that merits systematic investigation. To this end, this study sought to establish the extent to which the two-thirds gender policy was being applied in deployment of female teachers to headship positions.

\section{METHODOLOGY}

This study adopted a descriptive survey design. The researcher adopted this design because a large population could be studied with only a portion of that population being used to provide the required data (Kothari, 2004). The study was conducted in Nambale Sub-county, Busia County, which at the time of study had two educational zones namely East North Zone with 27 public primary schools and Central Zone with 18 public primary schools giving a total of 45 public primary schools. Nambale sub-county was purposely sampled because female teachers were in the majority but underrepresented in headship positions.

The study population was composed of 45 head teachers, 45 deputy head teachers, 427 assistant teachers, drawn from 45 public primary schools in Nambale sub-county, the District Education

${ }^{*}$ Corresponding author. E-mail: josephmukolwe@gmail.com.

Authors agree that this article remain permanently open access under the terms of the Creative Commons Attribution License 4.0 International License 
Table 1. Application of two-thirds gender policy in deployment of female teachers: Responses of male and female teachers.

\begin{tabular}{|c|c|c|c|c|c|c|c|c|c|c|c|c|c|}
\hline \multirow{2}{*}{ Statement } & \multirow{2}{*}{ Gender } & \multicolumn{2}{|c|}{ SA } & \multicolumn{2}{|c|}{ A } & \multicolumn{2}{|c|}{$\mathbf{U}$} & \multicolumn{2}{|c|}{ D } & \multicolumn{2}{|c|}{ SD } & \multicolumn{2}{|c|}{ Total } \\
\hline & & f & $\%$ & f & $\%$ & f & $\%$ & f & $\%$ & f & $\%$ & f & $\%$ \\
\hline Deployment policy provides & M & 29 & 33.9 & 21 & 35.6 & 0 & 0 & 17 & 28.8 & 1 & 1.7 & 59 & 100 \\
\hline Equal opportunities & $\mathrm{F}$ & 29 & 26.9 & 24 & 22.2 & 7 & 6.5 & 24 & 22.2 & 24 & 22.2 & 108 & 100 \\
\hline Female teachers not benefiting & $M$ & 13 & 22 & 20 & 33.9 & 4 & 6.8 & 16 & 27.1 & 6 & 10.2 & 59 & 100 \\
\hline From equal opportunities & $\mathrm{F}$ & 41 & 38 & 29 & 26.9 & 4 & 3.7 & 17 & 15.7 & 17 & 15.7 & 108 & 100 \\
\hline Female teachers discriminated & M & 6 & 10.2 & 16 & 27.1 & 2 & 3.4 & 27 & 45.8 & 8 & 13.5 & 59 & 100 \\
\hline Compared to male teachers & $\mathrm{F}$ & 4 & 38.9 & 36 & 33.3 & 6 & 5.6 & 15 & 13.9 & 9 & 8.3 & 108 & 100 \\
\hline Affirmative action policy & M & 16 & 27.1 & 6 & 10.2 & 4 & 6.8 & 21 & 35.6 & 12 & 20.3 & 59 & 100 \\
\hline Ensures equal and fair evaluation & $\mathrm{F}$ & 19 & 17.6 & 24 & 22.2 & 12 & 11.1 & 33 & 30.6 & 20 & 18.5 & 108 & 100 \\
\hline
\end{tabular}

Key: F-Female, f-frequency, M-Male, SA-Strongly Agree, A-Agree, D-Disagree, SD-Strongly Disagree and U-Undecided.

Officer (DEO) (Nambale Sub-county) and District Quality Assurance and Standard Officer (Nambale Sub-county), giving a total population of 519 respondents. Stratified sampling technique was employed to select head teachers, deputy head teachers and assistant teachers. Saturated sampling was appropriate for selection of the DEO and the District Quality Assurance and Standard Officer (DQASO) because they are the only senior management officers who are directly concerned with policy implementation and deployment of head teachers at the SubCounty level. Questionnaires, interview schedule guides and document analysis guide were the instruments of data collection.

The instruments were validated by experts in the School of Education at Jaramogi Oginga Odinga University of Science and Technology. Two male head teachers and one female head teacher were used to pilot the interview schedule. The validity and reliability of the interview schedule was done through data triangulation. A pre-test was done through administration of questionnaires to 2 male head teachers, 1 female head teacher, 2 male deputy head teachers, 1 female deputy head teachers, 2 male teachers and 2 female teachers. Internal consistency reliability, a measure of consistency between different items of the same constructs to deliver reliable scores, was determined using Cronbach's Alpha Test. Data were analyzed by calculating frequencies and percentages.

\section{RESULTS}

The main objective of this study was to establish the extent to which the two-thirds gender policy was being applied in deployment of female teachers to headship positions. Respondents were asked to indicate their opinion on the extent to which the two-thirds gender policy was being applied in deployment of female teachers to headship positions using a five point Likert scale. Table 1 summarizes the responses of male and female teachers concerning the extent to which the twothirds gender policy was applied in deployment of female teachers to head ship positions.

The findings in the Table 1 show that $69.5 \%$ of the male teachers agreed that deployment policy provided equal opportunity while $30.5 \%$ disagreed with the statement. On the other hand, $49.1 \%$ of the female teachers agreed with the statement as $44.4 \%$ were in disapproval. The findings suggested that the employment policy provided for equal opportunities as most, 50 $(69.5 \%)$, of males and, $53(49.1 \%)$, females agreed to this fact. These results were consistent with the gender policy in education of 2007 that stipulates gender equity and equality in recruitment, training, deployment and promotion, particularly in appointment of head teachers and deputy head teachers such that if the head teacher is male, the deputy is a female and vice versa (Republic of Kenya, 2007). The laws at present governing equal opportunities are enshrined in the constitution of Kenya2010 but Osoro (2014) observed that women were not coming out to go for top leadership positions by taking advantage of the constitution that provided for equal space for everyone.

These indicated the need for formulation of equal opportunity policies that were distinct from those subsummed in the current constitution of Kenya. The absence of specific equal opportunity policies made it difficult to ensure equality of opportunity because there was no yardstick against which day to day practices could be measured. Moreover, respondents were asked to indicate whether female teachers were not benefiting from equal opportunity policy. $55.9 \%$ of male teachers agreed that female teachers were not benefiting from equal opportunity policy for deployment to headship positions as $37.3 \%$ objected that idea. As pertains to female teachers, $64.9 \%$ were in agreement as $31.4 \%$ were in disagreement with the statement. This implied that no deliberate effort was being made by the Teachers Service Commission (TSC) and the MOE to ensure gender sensitivity and practice of equal opportunity policy. These results confirmed that deployment policy provided for equal opportunities but female teachers were not benefiting from this policy.

Similar views were expressed in a study conducted by Moorosi (2010) on South African female Principals' career path who argued that the extent to which equal opportunity policy interventions for advancement of female teachers to principalship were put in place and 
Table 2. Application of Two-thirds Gender Policy in Deployment of Female Teachers: Responses of Male and Female Deputy Head Teachers.

\begin{tabular}{|c|c|c|c|c|c|c|c|c|c|c|c|c|c|}
\hline \multirow{2}{*}{ Statement } & \multirow{2}{*}{ Gender } & \multicolumn{2}{|c|}{ SA } & \multicolumn{2}{|c|}{ A } & \multicolumn{2}{|r|}{$\mathbf{U}$} & \multicolumn{2}{|c|}{ D } & \multicolumn{2}{|c|}{ SD } & \multicolumn{2}{|c|}{ Total } \\
\hline & & $f$ & $\%$ & $f$ & $\%$ & $f$ & $\%$ & $f$ & $\%$ & f & $\%$ & $f$ & $\%$ \\
\hline Deployment policy provides & $\mathrm{M}$ & 8 & 30.8 & 7 & 26.9 & 2 & 7.7 & 5 & 19.2 & 4 & 15.4 & 26 & 100 \\
\hline Equal opportunities & $\mathrm{F}$ & 1 & 20 & 2 & 40 & 1 & 20 & 0 & 0 & 2 & 20 & 5 & 100 \\
\hline Female teachers not benefiting & $M$ & 5 & 19.2 & 11 & 42.2 & 3 & 11.6 & 4 & 15.4 & 3 & 11.3 & 26 & 100 \\
\hline From equal opportunities & $\mathrm{F}$ & 3 & 60 & 1 & 20 & 0 & 0 & 1 & 20 & 0 & 0 & 5 & 100 \\
\hline Female teachers discriminated & $M$ & 6 & 23.1 & 2 & 7.7 & 1 & 13.8 & 16 & 61.6 & 1 & 3.8 & 26 & 100 \\
\hline Compared to male teachers & $\mathrm{F}$ & 2 & 40 & 3 & 60 & 0 & 0 & 0 & 0 & 0 & 0 & 5 & 100 \\
\hline Affirmative action policy & $M$ & 1 & 3.8 & 3 & 11.5 & 2 & 27.7 & 12 & 46.2 & 8 & 30.8 & 26 & 100 \\
\hline ensures equal and fair evaluation & $\mathrm{F}$ & 0 & 0 & 0 & 0 & 0 & 0 & 2 & 40 & 3 & 60 & 5 & 100 \\
\hline
\end{tabular}

Key: F-Female, f-frequency, M-Male, SA-Strongly Agree, A-Agree, D-Disagree, SD-Strongly Disagree and U-Undecided.

achieved were not explored. The findings revealed that equal opportunities policy was enshrined in the law but female teachers were not reaping the rewards of equal opportunity enactment. This could imply that policy makers were not aware of gender specific hindrances in accessing school headship positions so that they could come up with policies that were gender responsive. Even after formulating the policies there was need to put machinery in place for monitoring and evaluation to ensure that the right procedures were followed in selection and deployment to headship positions.

Female teachers who were discriminated as compared to their male counterparts in deployment to school headship was supported by $37.3 \%$ of the male teachers as $59.3 \%$ were opposed. On the other hand, $72.2 \%$ of the female teachers agreed with the statement as $22.2 \%$ were in disagreement. There was a sharp disagreement on this statement by male and female teachers. A study conducted by Tsikata (2009) became important in this disagreement of opinions between male and female participants in the study sample. Tsikata (2009) asserted that indirect discrimination against women could occur when laws, policies and programmes were based on seemingly neutral criteria which in the actual effect had a detrimental impact on women. Gender neutral laws, policies and programmes unintentionally could perpetuate the consequences of past discrimination. Tsikata (2009) added that they could have been inadvertently modeled on male lifestyles, and thus failed to take into account aspects of women's life experiences which could have been different from those of men.

Following the same line of argument, Kamau (2010) pointed out that women were not always targeted for discrimination but were sometimes overlooked or not encouraged, mentored or supported and hence discrimination could have been therefore by default rather than by design. It could also have been as a result of prejudice about women's qualifications. The findings could suggest that although there was no open discrimination in terms of deployment to school headship, there could have been direct discrimination disguised in the requirements for deployment as there were no documented policies on equality of opportunity in deployment of teachers to headship positions by TSC. Therefore, TSC was not playing a proactive role in the goals of equality of opportunity in deployment of head teachers.

Male respondents who supported the idea of affirmative action policies ensuring equal and fair evaluation for deployment to headship positions formed $37.3 \%$ as $59.3 \%$ were not in support. Similarly, $39.8 \%$ of female teachers agreed with the statement as $49.1 \%$ were in disagreement. The findings from this data agreed with the general picture painted in the literature about the extent to which the two-thirds gender policy was being applied in advancement of women to leadership positions (Jane, 2014; Kagoda, 2011; Kaimenyi et al., 2013). This puts to doubt the effectiveness of the affirmative action policies in place. There could exist excellent policies on paper but they do little to advance qualified women into leadership. On leadership representation generally, the law was largely faithful to the principle of "no more than two thirds of one" gender in elective and appointive public positions. However, the affirmative action provisions have not helped female teachers to get leadership positions of public primary schools in the sub-county.

Table 2 presents a summary of the responses of male and female deputy head teachers concerning the extent to which the two-thirds gender policy was applied in deployment of female teachers to head ship positions. The findings in Table 2 showed that $57.7 \%$ of the male deputy head teachers perceived that deployment policy provided equal opportunities while $34.6 \%$ disagreed with the statement. On the other hand, $60 \%$ of female deputy head teachers agreed with the statement as $20 \%$ were in disapproval. The limited representation of women in school headship positions raised the questions about the effectiveness of equal opportunities policy and could have suggested its absence. The Chapter 27 of the constitution of Kenya-2010 provides for equality of rights and fundamental freedoms between men and women 
including equal opportunities in political, economic, cultural and social spheres and outlaws discrimination on any grounds (Republic of Kenya, 2010a). Although Kenyan government has scored well on formulating measures to address gender imbalance in leadership positions, it has failed to implement them to address the gender disparities in leadership of public primary schools in Nambale sub-county. In education, the Gender Policy in Education of 2007 gave recognition to equal opportunities (Republic of Kenya, 2007). However, these two mainstream legal documents were general and largely gender neutral and made no specific reference to female teachers or any affirmative measures to increase female teachers in participation of leadership of public primary schools.

With reference to female teachers not benefiting from equal opportunity policy, $61.4 \%$ of male deputy head teachers supported it as $27 \%$ disagreed with it. As $80 \%$ of female deputy head teachers agreed with the statement, $20 \%$ disagreed with it. Although in theory the merit principle is used to guide the selection of head teachers by TSC, most positions are filled on basis of trust and rapport or patronage (Republic of Kenya, $2012 b$ ). Despite the fact that the legislation required to improve gender equality was enshrined in the constitution of Kenya-2010, female teachers in the sub-county were still not having equitable access to leadership positions. This tended to undermine the rights and privileges already granted to women within the constitution. It could therefore be concluded that in principle the government supports gender equality but in practice there were no structural framework to promote it. Equal opportunity laws have proved inadequate to ensure equality in leadership positions of public primary schools in the sub-county.

Female teachers discriminated against compared to their male counterparts was supported by $30.8 \%$ of male deputy head teachers as $65.4 \%$ disagreed with it. As $100 \%$ of female deputy head teachers agreed with the statement, none disagreed with it. Research findings by Coleman (2009) indicated that women can be undervalued and deprived of leadership opportunities because of unfair selection or promotion procedures. The study by Coleman further revealed that organizations tended to hire or promote those candidates who resembled themselves. Therefore, where positions of authority were male dominated, women were underrepresented in leadership. Selection process that often favoured men had been well studied (Coleman, 2009; Qiang et al., 2009). The findings of these studies revealed that the unfairness in selection process resulted from women being judged informally and subjectively on basis of their perceived suitability for the post or for promotion by criteria such as age, relevance of experience and ability to "fit in". All these prejudices and biases restricted women opportunities to access and advance their career, which in turn discouraged and demotivated them because they were afraid that a desire for something they believe they "can never have" could lead to bitterness and unhappiness (Coleman, 2009; Qiang et al., 2009). This could be the situation with female teachers in Nambale sub-county because there was lack of anti-discriminatory enforcement structures.

The idea of affirmative action policy ensuring equal and fair evaluation was supported by $14.3 \%$ of male deputy head teachers whereas 77 and $100 \%$ of the male and female deputy head teachers respectively were in disagreement. It was evident from the finding that affirmative action did not provide for equal and fair evaluation of male and female teachers in deployment to head ship positions despite the constitution of Kenya 2010 stipulating that not more than two-thirds of elective and appointive posts should be of the same gender (Republic of Kenya, 2010a). These results showed that TSC had not taken specific measures within the existing constitutional policy provisions to provide equal rights between female and male teachers in participation of leadership of public primary schools. It could be deduced from the findings that other hindrances to female teachers' advancement to leadership positions compromised the principle of affirmative action. Participation of women in leadership and decision making bodies on equal terms with men is guaranteed in Kenya's constitution. Nevertheless, the presence of few female teachers in leadership positions of public primary schools in this subcounty defeated the equality implied in the constitution.

To investigate further the extent to which the two-thirds gender policy was being applied in deployment of female teachers to school headship positions in Nambale-Sub County, 29 male head teachers, 6 female head teachers, the DEO and the DQASO were interviewed by the researcher. Respondents were asked to explain how the Sub-county was implementing the two thirds gender policy in deployment of female teachers to headship positions. The responses to this question showed that the two-thirds gender policy in deployment of teachers to headship positions was a foreign concept in the Subcounty. According to the respondents two-thirds gender policy only existed in political realm. One of the female head teachers went further and pointed out that:

The two-thirds gender policy is focused on formal political representation aimed at increasing the number of female leaders and representatives. It is associated with reserved seats for women in politics but not leadership of public primary schools. Despite the progress made in regard to participation in political positions, we have not seen any effort made to make good of so called two-thirds gender policy when it comes to leadership of primary schools (Head Teacher 3).

This response showed that the validity of the two-thirds gender policy in deployment of teachers to headship position was questionable. Such responses were also noted by Winnie (2013) who commented that in spite of 
the two-thirds gender policy measures, there appeared to be very little impact in practice. She observed that in Kenya, concern about gender disparities in education had strongly focused on differences in access at various levels of schooling, student performance, particularly in terms of under achievement of girls evoking policies around gender gaps in education outcome. However, the question of gender disparities in management structures of schools had received very little attention. These findings indicated that the government intervention in ensuring equal opportunities was evident in the legislation. However, there was no practice of the principles of equality in deployment to leadership of public primary schools.

In Kenya, the government introduced affirmative action policy that required a third of all positions in management in education to be held by women (Republic of Kenya, 2005). Therefore, it could be inferred from these findings that there was no application of policy guidelines on gender equality policy and legislation had not supported the increase of the number of female school heads. This finding was in congruence with the report by Republic of Kenya (2010b) which revealed that despite the existence of the policies, legislative reforms, plans and programmes, gender disparities persisted in legal, social, economic and political levels of decision making, as well as access to and control of resources, opportunities and benefits.

The report attributed the slow implementation process mainly to gaps in laws, slow enactment of gender related legislation and lack of comprehensiveness in content of some laws. The implication of these findings was that there was a wide gap between formal policies and actual practices concerning the gender imbalance at school headship positions.

The respondents were next asked to explain how the female teachers were benefiting from equal opportunity policy on deployment of teachers to headship position in the Sub- County. In response to this question, 23 (62\%) of participants pointed out that the principle of equal opportunity had remained a marginal concern and a noncore issue in deployment of teachers to headship positions.

Responses to this question also indicated that the issue of equal opportunities did not arise in the deployment of teachers to headship position. The interview panels were expected to be fair and gender sensitive but no deliberate effort was made by the TSC to ensure gender sensitivity and equal opportunity. Such argument has been disputed by some scholars. For example, Tsikata (2009) lamented that gender neutral laws, policies and programmes unintentionally could perpetuate the consequences of past discrimination. Policy makers sometimes instituted affirmative policies but were unable to get them implemented. One female head teacher mentioned that:

Equal opportunities polices are not clearly defined and in most cases are flouted and bent to suit individuals ( Head
Teacher 14).

Therefore, equal opportunity policy which was designed by the government of Kenya as gender policy in education-2007, to ensure that both men and women had equal access to management and leadership positions in educational institutions was a phenomenon that was not emphasized and practiced in deployment of teachers to headship positions in this sub-county. These findings implied that the implementation of constitutionally guaranteed affirmative action measures meant to rectify gender imbalance in leadership and managerial positions was not practiced. Female teachers were not given priority in deployment to school headship positions as a matter of policy that aimed to redress current imbalance.

The respondents were further asked to comment on the impact of affirmative action policies on deployment of female teachers to headship positions in the sub county. Most, $21(57 \%)$, of interviewed participants pointed out rightly that affirmative action policies had no impact in practice. The views expressed by the respondents are shocking and surprising given that equal opportunity policies were enshrined in the constitution of Kenya-2010 which was the legal basis for affirmative action policies. These findings agreed with what had been found in Uganda (Kagoda, 2011) and South Sudan (Jane, 2014). Both the DEO and DQASO expressed concern that affirmative action policy was yet to be implemented despite the current level of gender sensitivity and the government demand for gender mainstreaming. They (DEO and DQASO) concurred that despite the fact that legislation to improve gender equality was enshrined in current Kenyan constitution-2010, there was a lot to be done in practice. The DEO noted that:

Women teachers increased participation in teaching force is not translating into increased numbers of women at headship positions.

\section{The DQASO mentioned that,}

Those equal opportunity policies have failed to respond to the real needs and expectations.

The responses of the DEO and DQASO showed that they did not seem to be prepared or capacitated to deal with issues related to enhancing female teachers' participation at headship positions. The same concern was echoed by a male head teacher who observed that:

...there were no deliberate efforts to implement affirmative action policy in education sector. Well- meaning laws and policies remain largely on paper. (Head Teacher 6).

This response demonstrated that the affirmative action policies used to address under representation of women in leadership position was either ignored or assumed 
altogether because document analysis did not find any documented policy on deployment of female teachers to headship positions. The documented policy which were mainly general were the constitution of Kenya - 2010, the gender policy in education (2007) and the presidential directive of 2006 on $30 \%$ women representation at decision making levels in employment, appointment, recruitment, promotion and training.

Tsikata (2009) lamented that whereas there were success stories of affirmative action policies in political representation around the world, lack of public policy commitment had undermined action measures in the education sector. The affirmative action policy was solely limited to political participation. These research findings indicated that the two thirds gender affirmative action policy for women representation was not fully implemented at all levels of government, especially in deployment of teachers to headship positions. Hence legislative requirements and policies that committed institutions to equality had not facilitated female teachers' advancement in leadership of public primary schools in the Sub-county. Female teachers having same qualifications as male teachers should have been given equal opportunities not only in theory but in practice. This indicated the need for effective policy framework to facilitate enhancement of female teachers' participation and representation at school headship positions.

\section{CONCLUSIONS}

Despite the existence of government policies on gender equality and equity in leadership, it was not practiced in deployment of teachers to headship positions in Nambale Sub-county which results in the question of contradiction between policy and practice.

Although appointment process to headship provided for equal opportunities, the study revealed that there was lack of transparency. There are no clear deployment and documented policies in place. Therefore, the appointment criteria are not made clear to everybody. This practice gave rise to speculation and suspicions about the criteria used in deployment. This went against the spirit of openness and rules of fair play in deployment to school headship. This had resulted into a skewed deployment pattern in which female teachers are underrepresented in school headship positions.

\section{RECOMMENDATIONS}

1. The TSC should come up with clear and documented policies that ensure equal opportunity for both male and female teachers. All information on available vacancies and interview results should be made public. As far as possible, deployment policies should be expressed in writing, reviewed and revised regularly to keep them updated and relevant. This is because written policies tend to be clear and precise and their compliance can easily be checked.

2. Machinery should be put in place for enforcement, monitoring and evaluation to see to it that the right procedures are followed in selection and deployment to headship position. This policy should be made to create a situation such that when the head teacher is male then the deputy head teacher should be female and vice versa.

\section{Conflict of Interests}

The authors have not declared any conflicts of interest.

\section{REFERENCES}

Akpinar-posito $C$ (2012). Career barriers for women executives and the glass ceiling syndrome: The case study comparison between French and Turkish women executives.Instanbul, Turkey: Elsevier Ltd.

Australian Government (2011). Promoting opportunities for all: Gender equity and women's empowerment. Australian Aid :Unpublished manuscript.

Barmao C (2013). Factors contributing to underrepresentation of female teachers in headship positions in primary schools in Kenya: A survey of Eldoret Municipality (Unpublished master's thesis). Moi University, Kenya.

Coleman M (2009). Women in educational leadership in England: Women leading education across continents.Plymonth, UK: Romans \& Littfield Education.

Davies ME (2011). Women on boards. Int. Res. Pract. 3(2):23-40.

Elborg-woytek K (2013). Women, work, and the economy: Macroeconomic gains from gender equity. Washington, DC: International Monetary Fund.

Elly J, Ibarra H, Kolb D (2011).Taking gender into account: Theory and design for leadership development programs. Acad. Manage. Learn. Educ. 10(3):2-51.

International Labour Organization (2012). Global employment trends for women. Geneva: ILO.

Jane K (2014). As strategy for achieving gender equality in South Sudan: Special report. Juba: Sudd Institute of Gender Fellowship .Retrieved from www. Sudd Institute.org.

Kamau N (2010). Women and political leadership in Kenya: Ten case Studies. Nairobi: Bollstiflung.

Kagoda M (2011). Gender equality. Looking beyond parity: Assessing the effectiveness of affirmative action on women's leadership and participation in education sector in Uganda. Geneva: UNESCO.

Kaimenyi C, Kinya C, Chege M (2013). An analysis of affirmative action: the two-thirds gender rule in Kenya. Int. J. Bus. Humanities Technol. 3(6):91-97.

Kochanowski M (2010). Women in leadership: Persistent problem or progress. Marist College, USA: Forum on Public Policy.

Kothari C (2004). Research methodology: Methods and techniques ( $2^{\text {nd }}$ ed). New Delhi: New Age International (p) limited.

Moorosi P (2010). South African female principals' career paths: Understanding gender gap in secondary school management. Gender Analysis of Educational Management Policies. 69:36-68.

Morley L (2013). Women and higher education leadership: Absence and aspirations. London: Leadership Foundation for Higher Education.

Onyango O, Simatwa W, Ondigi A (2011). Factors influencing participation of women in secondary school education management in Siaya District, Kenya: Analytical study. Int. Res. J. 2(9):15131527. Retrieved from http:www.interesjournals.org/ER

Osoro M (2014, December 12). Women professionals urged to fight for key posts. Standard Media Group: P 35.

Osumbah B (2011). Representation of women in top educational 
management and leadership positions in Kenya. Advancing Women in Leadership. $\quad 3157-68 . \quad$ Retrievedfrom http://advancingwomen.com/aw/aw/-word

Oti A (2013). Psychosocial and organizational climate factors as predictors of female academic career growth and leadership positions in South-West Nigerian Universities (Unpublished doctoral dissertation). University of Ibadan, Nigeria.

Parsaloi M (2012). Lived experiences of female head teachers in rural primary schools in Kenya (Unpublished master's thesis). University of South Africa, South Africa.

Qiang H, Han J, Niu X (2009). Chinese women participation in educational leadership. A review and analysis of the current situation. Plymouth, UK: Rowman \& Littlefield.

Republic of Kenya (2005). Sessional paper No.1 of 2005.Policy framework for education, training and research. Nairobi: Government printer.

Republic of Kenya (2007). Gender policy in education. Nairobi: Government Printer.

Republic of Kenya (2010a). The constitution of Kenya. Nairobi: Government Printer.

Republic of Kenya (2010b). Kenya's vision 2030. An audit from an income and gender inequalities perspectives. Nairobi: Society for International Development.

Republic of Kenya (2012a). Ministry of Education and Ministry of Higher Education, Science and Technology. Sessional Paper No 14 of 2012.A policy framework for education and training .Reforming education and training in Kenya .Nairobi: Government printer.

Republic of Kenya (2012b). Policy framework for education: Aligning education and training to the constitution of Kenya-2010 and the vision 2030 and beyond. Nairobi: Government printer.
Seliger S, Shames L (2009). White house project: Benchmarking Women's leadership. Washington, DC: Xerox.

Standard (2014, January 18). President ignored gender rule: Activists claim. Standard Media Group: pp. 1, 4.

Vassiliou A (2010). Gender differences in educational outcomes: A study on the measures taken and the current Situation in Europe. Brussels: The Education, Audiovisual and Culture Executive Agency (EACEA) .http://www. Unjdie, org.

World Bank (2012). World development report 2011: Gender equality and development. Washington DC: World Bank. 